\title{
Exploratory Study on Family Leisure Constraints of the Two- child Family in China
}

\author{
Caihong Zhang1, 2,*, Qiuya $\mathrm{Xu}^{3}$, and $\mathrm{Li} \mathrm{Zhu}^{3}$ \\ ${ }^{1}$ School of Management, Zhejiang University, 310058 Hangzhou, Zhejiang, China \\ ${ }^{2}$ School of Economics and Management, Pu'er University, 665000 Pu'er, Yunnan, China \\ ${ }^{3}$ School of Humanities, Pu'er University, 665000 Pu'er, Yunnan, China
}

\begin{abstract}
Driven by the two-child policy, there are more and more two-child families in China. The purpose of this research was to examine the leisure constraints of these families in Chinese urban areas. Based on interviews with the parents from 12 families and the leisure constraint theory, the main factors are identified. First, intrapersonal constraints, which include personal physical constraints (such as insufficient postpartum recovery) and psychological constraints(such as stress). Second, interpersonal constraints, which mainly come from family members (such as family support) and friends (such as narrowing social circles). Third, structural constraints, like family income, climate conditions, facilities, free time for leisure. Besides, the study also discovered a new type of constraint-cultural constraints, which is embodied in familism. This factor is close to the other three constraints and affects them. Based on this, the research proposed a new hierarchical model of leisure constraints. Finally, the article puts forward some suggestions for future research on family leisure under the influence of the two-child policy.
\end{abstract}

\section{Introduction}

In China, the long-term strict implementation of China' s one-child policy has led to demographic and social imbalances, such as the highest sex ratio at birth (SRB) in the world, 4:2:1 phenomenon (one couple solely responsible for the care of 1 child and 4 grandparents)[1]. By the end of 2012, the labor force in Mainland China had fallen for the first time since the Reform and Opening-up, a decrease of 3.45 million people compared with the previous year. Considering the shrinking population and aging workforce, in 2013, the Chinese government eased some restrictions of the one-child policy, and the married couples in which one of the spouses is an only child are permitted to have a second child. In 2015, the government announced that couples in China can have two children according to the universal two-child policy.

This policy not only promotes the arrival of the twochild era but also has a significant impact on the family relationship, family inter-generational structure, family life, and consumption patterns in China. However, after more than 30 years of the mandatory one-child era in Chinese families, the relaxation of this universal twochild policy has also brought new problems and challenges to many parents, such as the financial challenges from the high cost of housing, education, and health care for the children. And some previous researchers have proved that the number of children in a family has been identified as a determinant leading to a decrease in leisure expenditure [2].
Faced with the family changes brought about by the number of children, existing researches mainly discuss the impact of the two-child policy and the willingness to have a second child [3-5]. It is widely believed that twochild families are faced with tremendous pressure, such as work pressure, financial pressure as well as child care pressure. These pressures undoubtedly prohibit the leisure participation of two-child families. But leisure is a manifestation of people's rights and people's growing needs for a better life, and it is also closely related to people's quality of life. With the growth of income, leisure time and life extension, people's opportunity and potential to participate in leisure have greatly increased [6], and leisure consumption plays an important role in promoting the economy. Since the introduction of the universal two-child policy has not been long, research has paid very limited attention to leisure in two-child families. And this theoretical gap provides an opportunity for this study. Therefore, this research focuses on the leisure constraints of the urban two-child families in China under the implementation of the twochild policy and mainly discusses the following questions: What are the leisure constraints faced by the Chinese urban two-child families? How do these constraints affect leisure participation?

\footnotetext{
* Corresponding author: googgoog321@163.com
} 


\section{Literature review}

\subsection{Family leisure}

Family is considered to be the fundamental unit of society. It is an important place for people to practice leisure activities and form their cognition of leisure value. Family leisure primarily refers to the time that parents and their children spend together in free time or recreational activities [7]. Many scholars have expressed the recognition of the family leisure value. They believe that family leisure is one of the priority choices in various leisure activities. Family leisure provides opportunities to communicate and facilitate cohesive relationships for family members. Besides, it is also conducive to personal physical and mental health and development [8]. And themes of family leisure research mainly focus on the following three aspects: promoting family happiness through leisure, the cost and constraints of family leisure, and the leisure of marginal families [9]. It can be seen that family leisure and its constraints are important topics of leisure research.

As far as the concept of family is concerned, there are great cultural differences between China and the West. Specifically speaking, the nuclear family is the main model in western society, which usually consists of a couple and some minor children. While the Chinese family usually refers to extended family, including grandparents and other cousins of minor children [10]. Also, with the adjustment of social and economic structure, family leisure has undergone corresponding changes, and the two-child policy is one of the influencing factors. The implementation of the universal two-child policy has not only brought profound influences on the modernization of the economy, the adjustment of the demographic structure, the supply of labor but also made the family size expanded and the family relationship more complicated. At the same time, the implementation of the policy has injected new vitality into the study of family leisure.

\subsection{Leisure constraints}

Constraints refer to reasons for not engaging in a particular behavior, and leisure constraints can be viewed as a subset of reasons inhibiting people to participate in or spend more time doing leisure activities, making use of leisure services, or being satisfied with the leisure behavior [11]. Leisure constraints research aims to investigate factors limiting leisure preference formation and inhibiting or prohibiting participation as well as enjoyment in leisure [12]. Previous scholars have laid a theoretical foundation for subsequent research mainly from these two aspects: discussing the classification of leisure constraints and developing conceptual models of leisure constraints. For example, Francken and van Raaij believe that the internal barriers (personal interest, knowledge, capacity) and external barriers (time, money, circumstances, facility, and geographical distance) are constraints that block people from spending more time on some leisure activities [13].
Crawford and Godbey emphasized that family scholars have ignored investigating the barriers of family leisure participation. And they considered the leisure constraints to be intrapersonal, interpersonal, and structural barriers. These three types of leisure constraints have been widely adopted by scholars and have had a far-reaching influence. For the authors, intrapersonal barriers mainly refer to individual psychological states and attributes which interact with leisure preferences, such as stress, depression, anxiety, religiosity, and perceived self-skill. Interpersonal barriers are considered to be the outcome of interpersonal interaction or the relationship between individuals' characteristics, like the sex role attitudes of marriage partners and spousal decisions. And structural barriers represent constraints commonly conceptualized as intervening factors between leisure preference and participation. The examples involve family financial resources, season, climate, and so on [14].

On this basis, Crawford and other scholars proposed a hierarchical model of leisure constraints in 1991(see Fig.1), which further broadened the depth of research on leisure constraints. They believe that there is a certain hierarchical relationship among the three types of constraints: intrapersonal constraints, interpersonal constraints, and structural constraints. Intrapersonal constraints are the most basic but have the greatest influence, while structural constraints are the highest but have the least impact. Participation in leisure activities requires individuals to overcome one or all of the constraints. This hierarchical model also reveals the importance of exploring the leisure constraints mechanism.

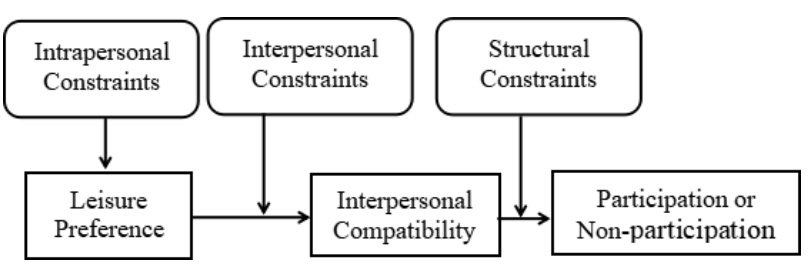

Fig. 1 A hierarchical model of leisure constraints

Though many scholars have made great efforts to move towards a deeper understanding of leisure constraints, the research is still limited. And most of the related research is still at the stage of describing and summarizing the influencing factors. Besides, the research on the mechanism that affects leisure participation is not sufficient, and little consideration is given to research about the particularity of the social environment or the influence of other background factors.

\section{Research design and methods}

This study mainly uses in-depth interviews to carry out research. It is one of the most important survey methods in qualitative research, which emphasizes the overall exploration of social phenomena in natural situations, using induction to analyze data and construct theories. The in-depth interview is a research method in which the 
scholar asks questions according to the research purpose, collects and constructs first-hand information from the subjects as evidence of their opinions [15]. Considering that the research question in this paper involves leisure constraints perception of second-child families, rich interview materials are conducive to a more comprehensive understanding and a conclusion closer to the facts. Therefore, the data collection in this study mainly adopts the interview method, which mainly centered on "What are the constraints on your leisure activities after having two children?", triggering a detailed discussion of the question. To collect detailed information, the interviewees are also encouraged to elaborate their views.

Due to the natural differences in family leisure and two-child birth concepts between urban and rural areas in China, this article limits the survey scope to the Chinese urban two-child families to ensure the pertinence of the research. Therefore, the two-child families in this study are those who have given birth to one child before the introduction of China's universal two-child policy and have given birth to two children after the implementation of the policy, and the birth time interval between the two children is from 1 to 5 years (in 2020, for the time interval as the cut-off point). To protect the privacy of the interviewee, the article uses "Family" and number to represent the family. The interviewee is the father or mother who raises two child and the interviews are conducted in the way of face to face interview, telephone interview, and network interview (such as WeChat). For half a year, 11 families were interviewed in this study, and each interview lasted 30 to 92 minutes. To improve the effectiveness of the interview content, audio recordings were made after obtaining the interviewees' consent, and the text materials were transcribed in time after the interview. When no new information appears in the interview, theoretical saturation is reached and data collection is ended.

\section{Results}

Leisure constraints will prohibit or hinder the quality, duration, intensity, and frequency of individual participation in leisure activities. Chinese urban twochild family leisure constraints involve intrapersonal constraints, interpersonal constraints, structural constraints, and cultural constraints, and a new hierarchical model of leisure constraints has been identified.

\subsection{Intrapersonal constraints}

Intrapersonal constraints mainly come from the individuals and are manifested in the following two aspects:

\subsubsection{Personal physical constraints}

Driven by the two-child policy, parents who choose to have a second child are generally older, most of whom are over 30 years old. The birth and care of the second child made these parents feel strenuous and did not have enough energy to participate in leisure activities. Some mothers even did not fully recover after the second childbirth, which also limited their participation in family leisure.

After giving birth to the first kid, I did not recover well. When the country allowed the birth of a second child, I was no longer young, and my physical strength and energy were not as good as before. I have to work. So it's really hard for me to take care of two children. I just want to sleep well when I have free time.

(Interview with mother in Family 11)

\subsubsection{Personal psychological constraints}

The stress perception of most parents with two children is very obvious, which leads to a decline in their leisure participation interest. Most parents said that after having their second child, they felt tremendous pressure in many aspects, such as the ability to raise children, family expenses, personal career development, and so on. Besides, the view of leisure also a constraint for some families.

In the past two years, I haven't made enough money in my business. I've been encountering problems. Agricultural investment has just started for one or two years. Unlike industrial investment, agricultural investment is large but slow to bear fruit. As for foreign trade, we used to make some money in the past, but now we are all at a loss. It's really difficult to earn money due to the complicated international relations. This year, some of my friends also agreed that the pressure of doing foreign trade is great. Besides, the family expenses are so large, leisure also needs money, so the most important thing at present is to make money to support the family.

(Interview with father in Family 05)

\subsection{Interpersonal constraints}

Interpersonal constraints are related to the mutual relations and interaction between individuals, family members, and friends.

\subsubsection{Constraints from family members}

The child's age, the child's physical condition, and the child's preference for leisure activities are important limiting factors for two-child parents to participate in family leisure. Also, the lack of family support by spouses and elders will greatly affect the possibility of family leisure.

Now I have two children, the second one is too young. Someone has to hold her when go out. Although the older one doesn't need to be hugged, he may run around and I will fail to keep up. There must be someone to keep an eye on him. Therefore, if no one can support me to go out together, I will not be able to go out with my two children.

(Interview with mother in family 06) 


\subsubsection{Constraints from friends}

Two-child parents said that after the birth of their second child, their social circle is more with the mothers. The narrowing of social scope also limits the depth and breadth of family leisure activities to a certain extent.

Before you have kids, you can go anywhere you want, and it is more convenient to hang out with friends. Now, being with two children, you can only make an appointment with friends who has one child or more children, and just talk about the children in the mother's circle.

(Interview with mother in Family 09)

\subsection{Structural constraints}

Structural constraints usually include factors such as the cost, time, geographic location, environmental facilities, and climate conditions for family leisure participation, which may limit the opportunities and realization of leisure for two-child families.

\subsubsection{Disposable free time}

Urban two-child families are usually dual-worker families. Both parents are busy with work or professional development, they usually have full schedules, or even work overtime, so they often lack free time for family leisure.

Busy at work, I have no time to take care of the children, let alone play with them. When I finish my work and return home, they may have fallen asleep.

(Interview with father in Family 04)

\subsubsection{Climatic conditions}

Even during the leisure time on weekends or holidays, family leisure will still be limited if the weather is bad.

Weather permitting, generally speaking, the whole family will go out on weekends. If the weather is bad and we take the child out, he will catch a cold easily. Apart from the cost of taking medicine, the child has to suffer, which is not worthwhile.

(Interview with mother in Family 08)

\subsubsection{Family income}

Although urban two-child families have double incomes, most parents still hold that raising two children requires a lot of expenses, such as children's education expenses, daily living expenses, and medical-related expenses, so they will reduce leisure activities accordingly to balance expenditure.

Consumption in cities is very high, and with the expenditure of raising two children, the family income is always insufficient. Although the elder one does not need tuition during the compulsory education stage, other trusteeships and interest training are very expensive. Besides, we have to buy milk powder for the second child. So nowadays, we rarely go to places with high consumption like children's playgrounds.
(Interview with mother in Family 11)

\subsubsection{Supply of recreational facilities}

Besides, the shortage of leisure resources and facilities is also an important factor restricting family leisure.

There are not enough places suitable for children to play, and you can't always run far away with your family just for fun.

(Interview with father in Family 05)

\subsection{Cultural constraints}

Two-child families have a unique understanding and cognition of the family's leisure meanings. The interview found that as a unique cultural value, familism is a key factor restricting family leisure. It refers to strong identification and attachment of individuals with their families as well as strong normative feelings of allegiance, dedication, reciprocity, and solidarity among members in the same family, both nuclear and extended [16]. Under the influence of familism, the principle for family members' thinking and actions is the family rather than personal interests. In the interview, the choice and practice of leisure activities for two-child families are influenced by affective commitment closely related to the family. Children are both the centripetal force and hope of Chinese two-child families. Parents and even grandparents usually gather together in leisure activities with children as the core, and show meticulous care for children in leisure activities, to achieve the common goal of family members, which is to cultivate a healthy and happy child who can undertake the development of the family.

Families are successful only when their children become successful. His mother and I are both busy making money and fighting for the growth of the child. The children are busy studying, and their Mom and I are busy earning money and fighting for their growth.

(Interview with father in Family 02)

Now everyone is fighting for kids. We spend most of our free time around our kids. Learning the "Three Character Classic", piano, calligraphy, painting, and other interest training, you have to keep up. For your kids, you have to make some sacrifices. All is done for the future of the kids. Only when they grow up well can there be hope.

(Interview with motherin Family 10)

\subsection{A refined hierarchical model of leisure constraints}

The further in-depth analysis found that intrapersonal constraints, interpersonal constraints, structural constraints, and cultural constraints are all closely related, and the last one's influence on the former three is very obvious.

Like filial piety to the elderly, taking care of children is also our responsibility. After all, children are the continuation of our lives and the hope of a family. Now 
that the child is born, the family should work together and try their best to raise him well.

(Interview with father in Family 02)

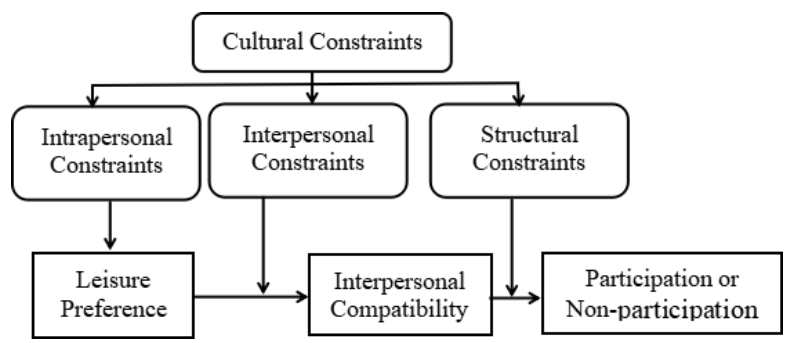

Fig.2 The refined hierarchical model of leisure constraints

Based on this, the researchers refined the hierarchical model of leisure constraints and proposed a new mechanism model for the Chinese urban two-child families, as shown in Figure 2.

\section{Conclusion and discussion}

Using qualitative research and in-depth interview method, this paper takes 12 Chinese urban two-child families as the survey objects and conducts exploratory research on the leisure constraints and mechanism for the two-child families in Chinese cities. It has been found that the leisure constraints of two-child families in Chinese cities do not only involve intrapersonal constraints, interpersonal constraints, and structural constraints but also relate to the cultural constraints of Chinese society. The culture of familism makes twochild parents pay more attention to their families, especially the health and development of their children, and be willing to sacrifice personal interests to share family happiness with their families. The research on leisure constraints should view culture as a constraint. And this research provides theoretical support for this argument from an empirical point of view. Meanwhile, the research has also revised the leisure constraints model proposed by Crawford and other scholars. This result not only provides some new discoveries and interpretations of family leisure constraints but also reveals that the study of leisure constraints is inseparable from a specific social and cultural background. It also should be pointed out that this paper still has some limitations in terms of research methods, and it needs to be combined with quantitative research in the future to further verify the correctness of the conclusion and model. Besides, for the research on leisure constraints of urban two-child families, topics worth further discussion include the negotiation strategies of leisure constraints, the relationship between leisure constraints and leisure participation, and the impact of leisure constraints on health and leisure satisfaction.

\section{Acknowledgments}

This work was supported by the 2019 Academic and Technical Youth Leaders Project of Pu'er University (QNRC1901), the 2020 Academic and Technical Youth Leaders Project of Pu'er University (QNRC20-04), and
Projects of Local Ethnic Culture Research Canter of Pu’er University (2020LHZX01).

\section{References}

1. Hesketh, T., Zhou, X., \& Wang, Y. (2015). The end of the one-child policy: lasting implications for China. Jama, 314(24): 2619-2620.

2. Lima, J., Eusébio, C., \& Amorim Varum, C. (2018). Determinants of leisure expenditure: Do low-income families behave any differently from others?. Anatolia, 29(1): 24-39.

3. Gong, W., Xu, D. R., \& Caine, E. D. (2016). Challenges arising from China's two-child policy. The Lancet, 387(10025): 1274.

4. Zeng, Y., \& Hesketh, T. (2016). The effects of China's universal two-child policy. The Lancet, 388(10054): 1930-1938.

5. Ji, Y., Wang, H., Liu, Y., Xu, R., \& Zheng, Z. (2020). Young Women's Fertility Intentions and the Emerging Bilateral Family System under China's Two-Child Family Planning Policy. China Rev., 20(2): 113-142.

6. Godbey, G. (2003). Leisure in Your Life: An Exploration. Venture Publishing, State College.

7. Shaw, S. M. (1997). Controversies and contradictions in family leisure: An analysis of conflicting paradigms. Leis. Res., 29(1): 98-112.

8. Zabriskie, R. B., \& McCormick, B. P. (2001). The influences of family leisure patterns on perceptions of family functioning. Fam. Relat., 50(3): 281-289.

9. Hodge, C., Bocarro, J. N., Henderson, K. A., Zabriskie, R., Parcel, T. L., \& Kanters, M. A. (2015). Family leisure: An integrative review of research from select journals. J. Leis. Res., 47(5): 577-600.

10. Bai K, Fu G. (2011). Perspective of the theory of localization in the study of family travel decisionmaking and train of thoughts for analysis. Tourism Tribune, 26(12): 49-56.

11. Jackson, E. L. (1988). Leisure constraints: A survey of past research. Leis. Sci., 10(3): 203-215.

12. Jackson, E. L. (2000). Will research on leisure constraints still be relevant in the twenty-first century?. J. Leis. Res., 32(1): 62-68.

13. Francken, D. A., \& Van Raaij, W. F. (1981). Satisfaction with leisure time activities. J. Leis. Res., 13(4): 337-352.

14. Crawford, D. W., \& Godbey, G. . (1987). Reconceptualizing barriers to family leisure. Leisure Sciences, 9(2): 119-127.

15. Chen X. (2000). Qualitative Research Methods and Social Science Research (first edition). Educational Science Press, Beijing.

16. Sabogal, F., Marín, G., Otero-Sabogal, R., Marín, B. V., \& Perez-Stable, E. J. (1987). Hispanic familism and acculturation: What changes and what doesn't?. Hisp. J. Behav. Sci., 9(4): 397-412. 